\title{
PUSAT INFORMASI PARIWISATA DAN KEBUDAYAAN SULAWESI SELATAN DENGAN PENDEKATAN ARSITEKTUR MODERN
}

\author{
Andi Nur Fadillah ${ }^{1}$, Taufik Arfan ${ }^{2}$, Irma Rahayu ${ }^{3}$ \\ Jurusan Arsitektur Fakultas Sains \& Teknologi UIN Alauddin Makassar \\ E-mail ; Dilladi54@yahoo.com, taufik.arfan@gmail.com,irmamgee@yahoo.co.id
}

\begin{abstract}
Planning and designing aim to design a culture and tourism information center with Modern Architecture Approach, the design limited on several issues there are the architectural issues, particularly spatial, space requirements and appearance of the building, while the method used is the study of literature / literary studies, surveys (form of field observation and data collection of building where has a similar function to the culture and tourism information center) and analyzing the data obtained. The result of the design is the creation of culture and tourism information center in Makassar, South Sulawesi with Modern Architecture approach with the ability of the building to accommodate the times when the building is nuance and modern look, with a modern form so that this building is more Interesting to prospective visitors.
\end{abstract}

Keywords ; information, tourism, culture, modern.

\footnotetext{
${ }^{1}$ Alumni Jurusan Teknik Arsitektur UIN Alauddin Makassar Angkatan 2008

${ }^{2}$ Dosen Jurusan Teknik Arsitektur UIN Alauddin Makassar

${ }^{3}$ Dosen Jurusan Teknik Arsitektur UIN Alauddin Makassar
} 


\section{PENDAHULUAN}

\section{Latar Belakang}

Citra pariwisata dan kebudayaan Sulawesi Selatan pada dasarnya mempunyai keragaman produk yang tersebar di seluruh nusantara dan memiliki keragaman bio diversity flora dan fauna yang telah memberikan daya tarik wisatawan dalam kegiatan wisata alam. Keragaman etnis, bahasa, budaya, peninggalan sejarah, tradisi serta kehidupan masyarakat mampu memberikan daya tarik wisatawan yang menjadi minat khusus yang mendapat perhatian dari wisatawan dunia. Kenyataan di atas memposisikan Sulawesi Selatan mempunyai peluang besar mempromosikan keanekaragaman wisatanya, dan dapat bersaing dengan produk wisata dari provinsi lainnya. Objek wisata yang terdapat di Sulawesi Selatan sangat beragam dengan berbagai corak yang sangat spesifik seperti wisata alam, wisata budaya,wisata bahari, wisata hiburan atraksi dan lain-lain. Meskipun demikian, masih banyak di antaranya yang luput dari kunjungan wisatawan Berdasarkan hasil survey di lapangan di mana setiap tahunnya pengunjung wisatawan yang semakin meningkat walaupun secara fluktuatif perlu ditingkatkan pula pelayanan yang ada di bidang pariwisata dan kebudayaan yang memberikan informasi yang mencakup wisata dan budaya yang ada di Sulawesi Selatan. Jumlah Wisatawan mancanegara maupun wisatawan Nusantara yang berkunjung ke Sulawesi Selatan dari tahun ke tahun menunujukkan peningkatan,meskipun peningkatannya dari tahun ketahun fluktuatif, tahun 2007 jumlah wisatawan Nusantara 1.212 .982 kemudian tahun 2008 naik menjadi 2,032.021,tahun 2010 dari 3.768.252 meningkat di tahun 2011 menjadi 4.471.632, sedangkan wisman tahun 2010 yakni 42.371 meningkat di tahun 2011 menjadi 51.749 kedatangan. Di Sulawesi Selatan belum terdapat pusat informasi pariwisata dan kebudayaan yang menyediakan tempat untuk semua kegiatan pariwisata dan kebudayaan yang lebih mengekspos dan mengiklankan serta memperlihatkan tempat wisata dan keanekaragaman budaya serta pertunjukannya. Bertolak dari latar belakang di atas, maka idealnya terdapat suatu tempat sarana pusat informasi pariwisata dan kebudayaan Sulawesi Selatan di Makassar yang strategis, sehingga dapat mengakomodasi kebutuhan informasi tentang wisata dan budaya-budaya yang ada di Sulawesi Selatan.

\section{RUANG LINGKUP \& BATASAN PEMBAHASAN}

\section{Lingkup Pembahasan}

Lingkup pembahasan dibatasi pada pemecahan permasalahan yang berkaitan dengan perencanaan dan perancangan sebuah bangunan pusat informasi pariwisata dan kebudayaan yang merupakan tempat pemusatan aktivitas untuk pelayanan informasi yang berhubungan perjalanan pelancongan dan sesuatu yang turun temurun dari satu generasigenerasi yang lain tentang pengetahuan, kepercayaan, kesenian, moral, adat istiadat yang di dapat seseorang dari anggota masyarakat.

\section{Batasan pembahasan}

a. Pusat informasi pariwisata dan kebudayaan mewadahi kegiatan-kegiatan informasi dan pameran budaya dan pariwisata

b. Masalah perancangan dibantasi pada masalah arsitektural, khususnya tata ruang, persyaratan ruang dan penampilan bangunan.

c. Perancangan didoasarkan pada standar-standar ruang yang telah dianalisis dan dibahas pada acuan perancangan yang disesuaikan dalam proses perancangan fisik. 
d. Masalah struktur dan utilitas dibatasi pada masalah yang berkaitan langsung dengan sistem yang sesuai dengan rancangan bangunan ruang mesin pompa, ruang genset dan fasilitas penunjangnya.

\section{METODE PEMBAHASAN}

Metode pembahasan yang digunakan adalah metode deskriptif analisis, yaitu metode pembahasan dengan menguraikan komponen masalah dan kaitannya secara keseluruhan, dengan cara mengidentifikasi masalah yang ada, menganalisa dan menyimpulkan berdasarkan studi pustaka, penelitian dan wawancara.Kesimpulan yang ada digunakan untuk menyusun konsep dasar perencanaan yang selanjutnya diterapkan dalam perencanaan fisik bangunan.

\section{KONSEP \& STRATEGI PENDEKATAN ARSITEKTUR MODERN}

\section{Konsep Arsitektur Modern}

Arsitektur modern adalah suatu istilah yang diberikan kepada sejumlah bangunan dengan gaya karakteristik serupa, yang mengutamakan kesederhanaan bentukdan menghapus segala macam ornamen. Pertama muncul pada sekitar tahun 1900. Pada tahun 1940 gaya ini telah diperkuat dan dikenali dengan Gaya Internasional dan menjadi bangunan yang dominan untuk beberapa dekade dalam abad ke 20 ini. Beberapa sejarawan melihat perkembangan arsitektur modern sebagai perihal sosial yang kelak kaitannya terhadap pembaharuan dan keringanan, suatu hasil dari perkembangan sosial dan politis. Arsitektur lainnya yang melihat gaya modern sebagai sesuatu yang di kendalikan oleh teknologi dan pengembangan produk dan dengan munculnya bahanbahan yang dipakai dalam membangun gaya bangunan modern seperti material besi, baja, kaca dan beton menambahkan pengetahuan bahwa gaya modern adalah sebuah penemuan baru dalam bidang revolusi industriArsitektur modern umumnya ditandai dengan penyederhanaan bentuk dan penciptaan ornamen dari struktur dan tema bangunan. Ini adalah istilah yang digunakan untuk gerakan menyeluruh, dengan definisi yang tepat dan ruang lingkup yang bervariasi secara luas

\section{Stragtegi Pendekatan Arsitektur Modern}

Strategi pendekatan arsitektur modern yang digunakan pada bangunan pusat penjualan buku tersebut yaitu pada bentuk bangunan yang bersifat modern disertai material-material yang digunakan pada bangunan tersebut, bentuk bangunan yang bersifat modern akan mengundang para pencinta buku untuk mengunjungi bangunan tersebut di tambah dengan fasilitas penunjang yang ada pada bangunan diantaranya ruang pameran buku, ruang cetak buku, ruang penerbit, ruang konsultasi ebook, fasilitas wifi, dan sebagainya. 

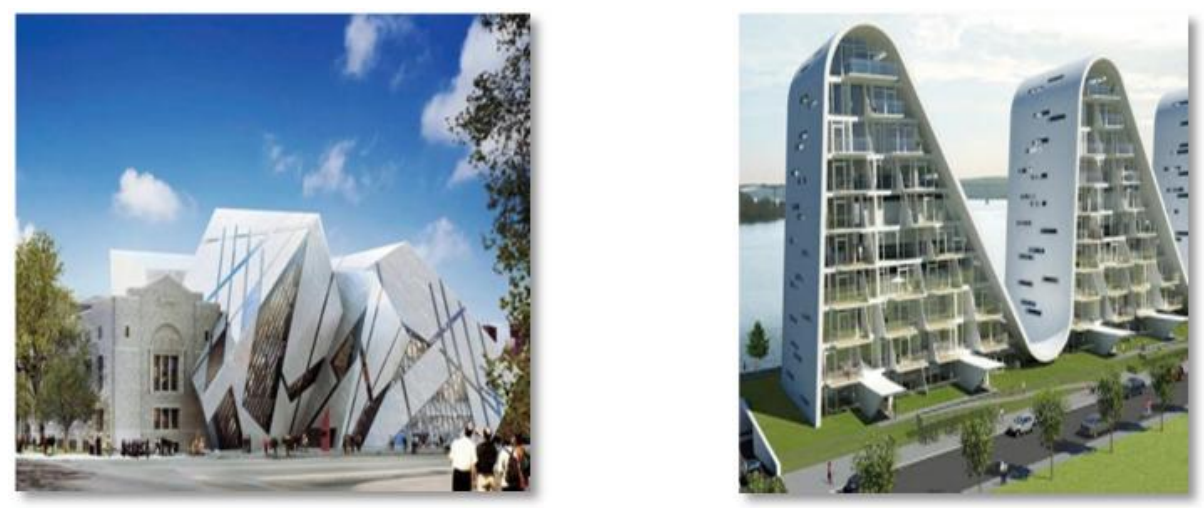

Gambar 1. contoh bangunan berarsitektur modern (sumber : //http.www.googgle.com/arsitektur Modern diakses 15 november 2012)

\section{HASIL PERANCANGAN}

\section{Lokasi Perancangan}

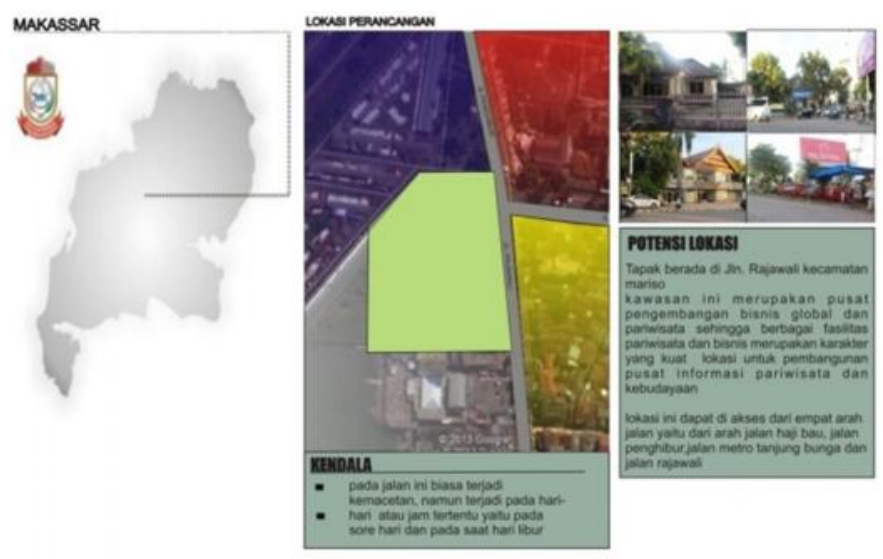

Gambar 2 Lokasi peranangan (sumber : analisis pribadi)

\section{View Bangunan}

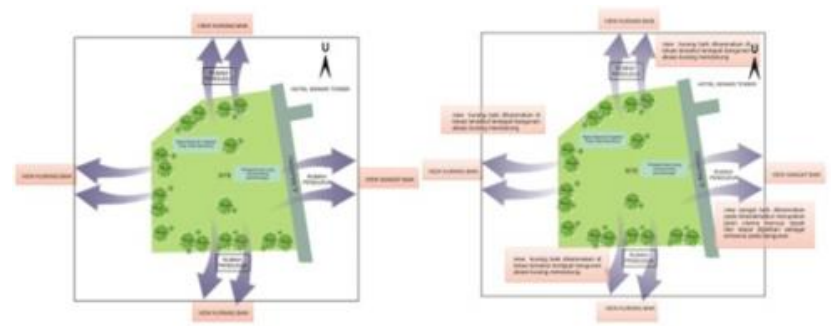

Gambar 3. Lokasi peranangan (sumber : analisis pribadi) 


\section{Site Plan}

Nama Proyek : Pusat informasi pariwisata dan kebudayaan Sulawesi selatan dengan pendekatan arsitektur modern

Lokasi Proyek : JL. Rajawali

Luasan Tapak : $1.3 \mathrm{Ha}$

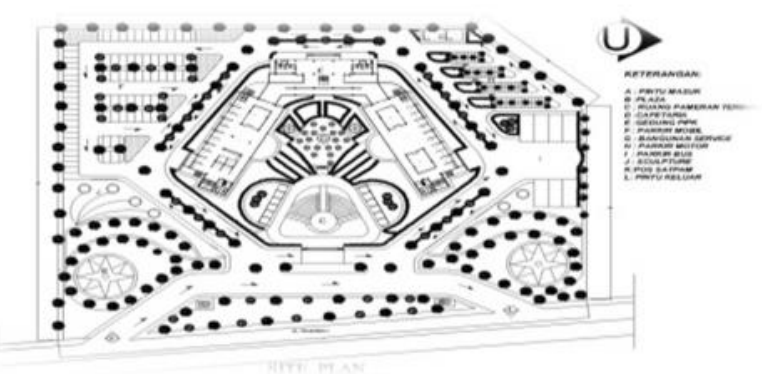

Gambar 4. Lokasi peranangan (sumber : analisis pribadi)

\section{Bentuk Bangunan}

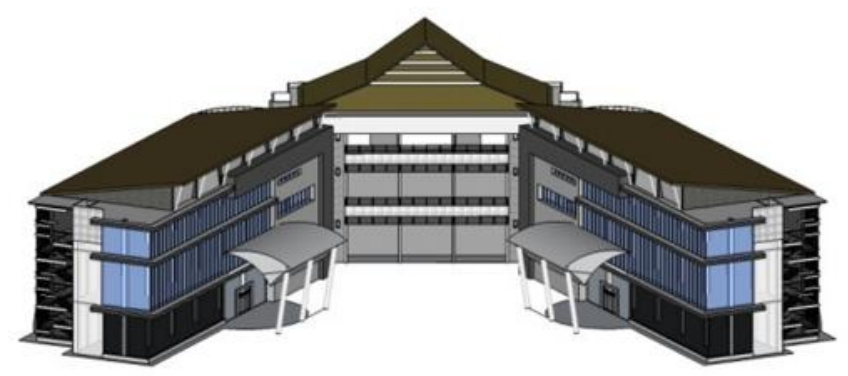

Gambar 5. Lokasi peranangan (sumber : analisis pribadi)

Pusat Informasi Pariwisata dan kebudayaan Sulawesi Selatan akan menjadi sarana informai bagi masyarakat umum, sehingga dalam penampilannya bangunan harus bersifat terbuka, menarik

\section{Selubung Bangunan}

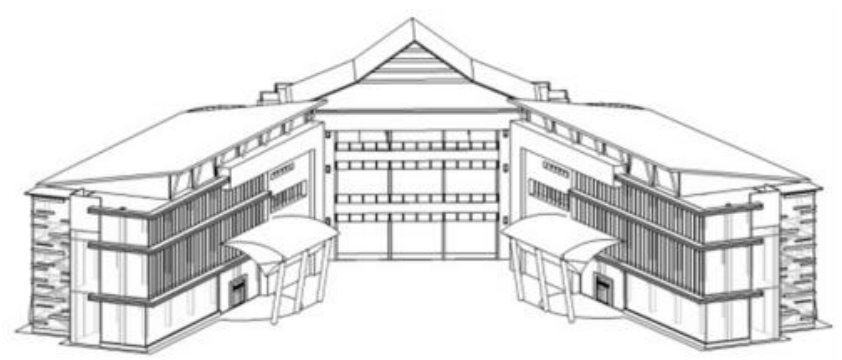

Gambar 6. Lokasi peranangan (sumber : analisis pribadi) 
Nature

\section{Struktur}

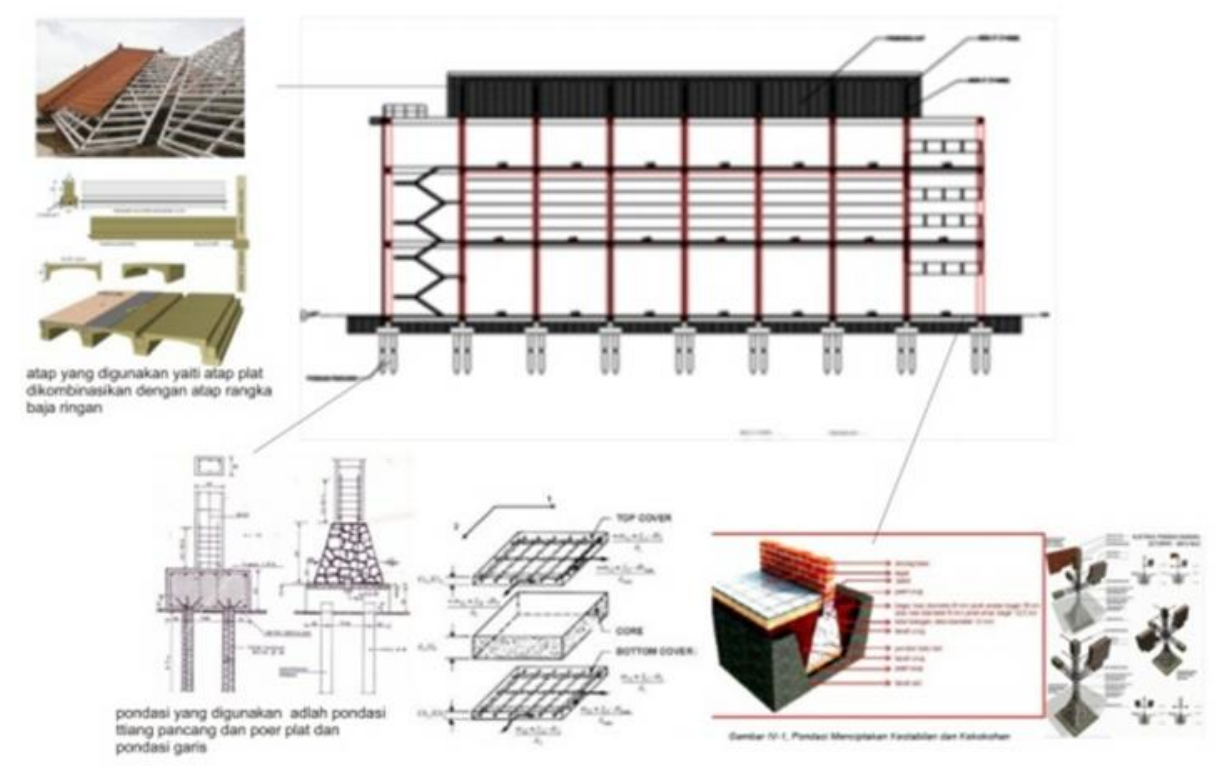

a. Sub Struktur

Struktur atap dengan menggunakan plat beton dikombinasikan dengan rangka baja dapat

b. Middle struktur

Pada bangunan yang direncanakan menggunakan material beton bertulang pada kolom dan balok

c. Sistem sub struktur

yang direncanakan adalah pondasi tiang pancang, poer dan pondasi garis. Konstruksi yang digunakan adalah kontruksi baja dan konstruksi beton bertulang.

\section{Material}
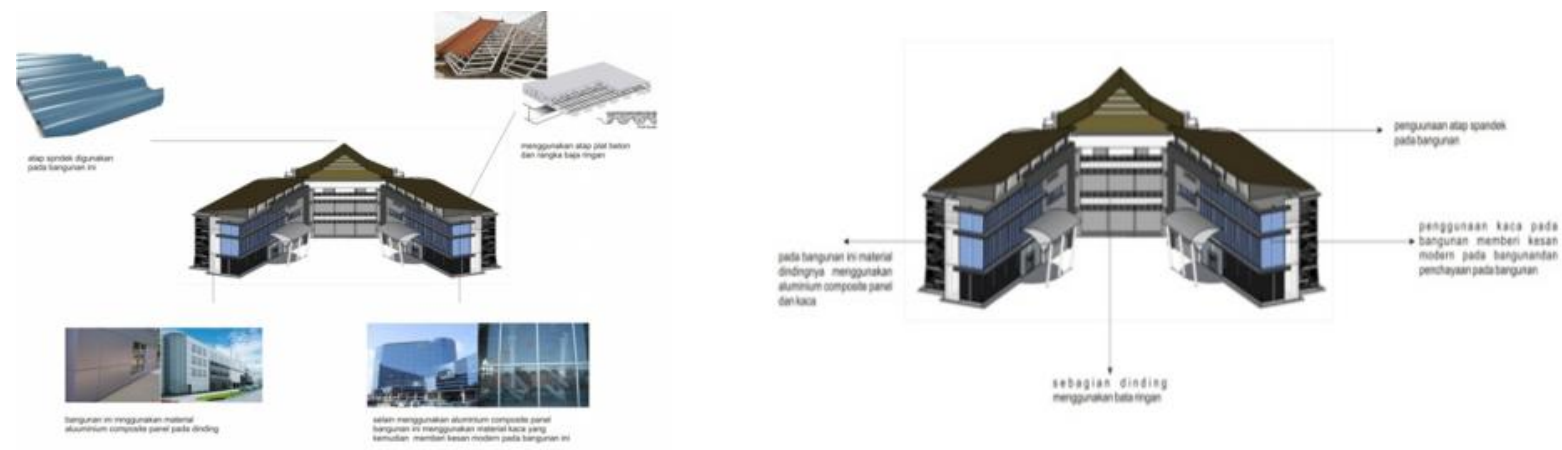

Material bangunan yang diterapkan pada bangunan tersebut diantaranya ACP pada dinding luar, Dinding Kaca, Rangka Baja Ringan, Atap spandek, Dinding Partisi Kalsi dan sebagainya. 


\section{DAFTAR PUSTAKA}

Badan Pusat Statistik, (2011), Makassar Dalam Angka 2011, Laporan, Pemerintah Daerah Kota Makassar.

Nur Fadillah, Andi (2012), Pusat informasi pariwisata dan kebudayaan Sulawesi Selatan dengan Pendekatan Arsitektur Modern, Acuan Perancangan, Universitas Islan Negeri Alauddin Makassar , Makassar.

Neufert, Ernst, 1999, Data Arsitek, Edisi Kedua, Jilid II, Terjemahan Sjamsu Amril, Jakarta : Erlangga.

Neufert, Ernst, 2000, Neufert Architects’ Data, Third edition, Blackwell PublisingRasmawati. (2005), Book Store

di Makassar, Skripsi, Universitas Hasanuddin,

Makassar.

Dinas kebudayaan dan kepariwisataan provinsi

sulsel. Analisa informasi pasar 2011, Sulawesi

selatan 
Nature

National Academic Journal of Architecture 